\title{
Do circulating HIV vaccine plasmids contribute to immunogenicity in humans? \author{
and $A$ Bråve
} \\ B Wahren*, G Engström, K Aperia, L Gudmundsdotter, E Sandström, J Albert
}

Address: Swedish Institute for Infectious Disease Control, Karolinska University Hospital and Karolinska Institute, Stockholm, Sweden

Email: B Wahren* - Britta.Wahren@smi.ki.se

* Corresponding author

from 2006 International Meeting of The Institute of Human Virology

Baltimore, USA. 17-21 November, 2006

Published: 2I December 2006

Retrovirology 2006, 3(SuppI I):P64 doi:10.1 186/1742-4690-3-SI-P64

(C) 2006 Wahren et al; licensee BioMed Central Ltd.

\section{Background}

We conduct a phase 1 clinical trial where forty healthy volunteers are immunized with multigene, multiclade HIV DNA plasmids encoding nine different proteins of HIV-1 subtypes.

\section{Materials and methods}

Total nucleic acid was extracted from plasma or sera. A nested PCR was performed using specific primers designed for the vaccine plasmids and HIV-1 DNA PCR directed against HIV genes not present in the vaccine.

\section{Results}

Two months after the third immunization, an HIV RNA quantitative PCR was performed to confirm the noninfected status of the participants. In half of the vaccines, in total receiving 3-12 mg plasmid DNA, we noted reactions of plasmid DNA or values corresponding to 201200 HIV RNA copies in the Roche Amplicor assay. Env and/or gag encoding plasmids were detected in the plasma or serum of the vaccines, but no HIV. A PCR for HIV protease (the protease gene is not included in the vaccine) was negative in all cases. Antigen and antibody assays have confirmed that the individuals were not infected. The study is still blinded, but a total of over $90 \%$ have responded very well by T-cell assays.

\section{Conclusion}

HIV vaccine plasmids given id or im were identified as late as two months after immunization. A relation between immunogenicity and circulating vaccine plasmids will be sought. DNA plasmids may give positive signals in a standard HIV RNA quantative assay. 